\title{
NATURAL INFECTION OF SPARGANUM IN FROGS IN NAGALAND (NORTHEASTERN INDIA) - AN AMPHIBIA-BORNE ZOONOSIS?
}

\author{
Veena Tandon ${ }^{1}$ and R. Imkongwapang ${ }^{2}$ \\ ' (Corresponding author) Department of Zoology, North-Eastern Hill University, Shillong 793 022, Meghalaya, India. \\ E-mail:vtandon@nehus.ren.nic.in \\ ${ }^{2}$ Department of Zoology, North-Eastern Hill University, Shillong 793 022, Meghalaya, India \\ Fax: 91364250076
}

\begin{abstract}
Several species of anuran Amphibia in Nagaland (northeastern India) were found to harbour Plerocercoid (=Sparganum) larvae of Sprirometra species of Cestodes in their muscle tissue the adults of which occur as intestinal parasites in felids and canids. In view of their use in traditional medicine and local cuisine among the native tribals, these frog species may possibly be involved as paratenic hosts in dissemination of sparganosis as a zoonosis among human hosts in the region.
\end{abstract}

\section{Key words}

Sparganum, zoonosis, paratenic hosts, amphibians

\section{Introduction}

Associations of amphibians with several zoonotic infections have been frequently reported, particularly in southeast and far eastern countries where eating of frogs and treatment of wounds with raw flesh of frogs is customary (Hoeden, 1964; Suzuki et al., 1982; Shen, 1988; Arora, 1994; Bodri, 1994; Mastura et al., 1995a,b). Amphibians are implicated as one of many paratenic hosts for the pseudophyllidean tapeworm of the genus Spirometra, adults of which are common mammalian parasites, particularly in cats and dogs (Miyazaki, 1991). According to the same authority, only one species of Spirometra is represented in Asia: S. erinacei (= mansoni). This cestode is of medical importance as its larval stage, the plerocercoid (= sparganum), causes sparganosis in humans (Huang \& Kirk, 1962; Tansurat, 1966; Kittiponghansa et al., 1988). Spirometra involves two intermediate hosts in its life cycle; the first is a copepod (Cyclops) in which the Procercoid larval stage develops and the second may be either frog, snake, bird or mammal in which spargana are found in the muscle tissue (Kobayashi, 1931; Mueller, 1938; Iwata, 1972). Humans become infected by three possible routes -through copepod-contaminated drinking water, by ingestion of raw or partially cooked frog or snake-flesh contaning spargana (which migrate through the intestinal wall and encyst in the subcutaneous tissue) and through direct contact by application of frog/snake flesh poultice on open wounds.

\section{Material and Methods}

Study area

The study area comprises three major localities in the state of Nagaland, northeastern India, which offer varied climatic conditions which are expected to have an impact on the abundance of both amphibian hosts and their parasitic fauna. Of the localities under survey (Fig. 1), Kohima (which is the state capital, district headquarters and the abode of Angami tribe) lies at the foot hill of Japhu Peak, the secound highest peak in Nagaland, covering an altitude range of $1444.12-1590+/$ $-5 \mathrm{~m}$., has high rainfall, mild temperature in summer ranging from $12-21^{\circ} \mathrm{C}$ and cold in winter with average temperture ranging from $1-6^{\circ} \mathrm{C}$. Mokokchung, situated to the Northeast of Kohima, is another district headquarters and the abode of the Ao tribe; its altitude ranges from $1000-1400 \mathrm{~m}$.; the rainfall is high and the temperature is mild to cold through the year, ranging from 8.6 $25^{\circ} \mathrm{C}$ and most of the time it is misty and cloudy; the rainy season starts from the month of May and lasts till October (some times until December). Dimapur, another district headquarters and a fast growing commercial town, is identical to any of the tropical plains with an altitude ranging between $195-260 \mathrm{~m}$. and has a hot and humid climate for most part of the year.

\section{Hosts collected/surveyed}

The anuran hosts collected and examined for plerocercoid infection included in all 13 species under six genera representing 3 families (identified following Dutta, 1997). These included Euphlyctis cyanophlyctis, Limnonectes limnocharis, $L$. mawphlangensis, Rana khare, R. liebigii, Rana sp., 
Hoplobatrachus tigerinus, Scutiger(?) sp., Rhacophorus reinwardtii, $R$. nigropalmatus, Polypedates leucomystax, Hyla annectens and Amolops afghanus. Collections were carried out in different spots in the main localities mostly by day or at nightfall, either with a net or hands following the croaking sounds of the males or by locating the nest constructed by the female in a few species.

\section{Methodology}

In captivity, anurans do not feed and tend to get rid of their worm burden (Smyth \& Smyth, 1980). Therefore, immediately after capture, they were narcotised, dissected or autopsied after returning to the laboratory. Muscles of the limbs, peritoneal cavity and its wall and abdomen of the host were examined. For whole mount preparation, parasites were first stretched in warm water, flattened and fixed in $70 \%$ alcohol, stained with borax carmine, followed by dehydration in ascending gradean of alcohol, followed by clearing in methyl benzoate and mounting in canada balsam.

For scanning electron microscopy, live specimens recovered were fixed in $4 \%$ cold neutral phosphate buffered formalin, dehydrated in ascending grades of acetone and treated with tetramethylsilane following Roy and Tandon (1991), metal coated in a fine coat ion sputter JFC-1 100 (JEOL) and observed under a scanning electron microscope JSM 35CF (JEOL) under an electron accelerating voltage ranging between 10 and $20 \mathrm{kV}$.

\section{Observations}

Numerous specimens of a plerocercoid larval form were recovered during the study period from all the three major localities of Nagaland surveyed. The maximum number of parasites in an infected host was 18. Of the host species surveyed, the plerocercoid infection was found to occur only in six. The prevalence and intensity of plerocercoid infection is depicted in Table 1. The parasite measured $50.2-75.1 \mathrm{~mm}$ in length. In slightly contracted form, its apical end showed the presence of a frontal pit. Under scanning electron microscope its body surface is revealed to have numerous transverse folds or wrinkles giving it a pseudosegmented appearance, with slight suggestion of the beginning of proglottidization. Under higher resolution the whole tegumental surface is shown to have dense covering of microtriches. The latter did not show any regional differentiation of their shape and density (Figs. 2-6).

\section{Discussion}

Plerocercoid larvae have earlier been reported from several amphibian hosts, such as, Euphlyctis cyanophlyctis, Hoplobatrachus tigerinus, Limnonectes limnocharis and Rhacophorus nigropalmatus from Meghalaya in northeastern India (Diengdoh, 1989). The present report forms a new locality report with Rana sp. from Dimapur, Rhacophorus reinwardtii "from Kohima and Polypedatus leucomystax from Mokokchung and Dimapur as new host host records. Polypedatus leucomystax was always found to be the most heavily infected of all the host species checked for infection.

The plerocercoid larvae, studied herein, showed a similarity in morphology to Spirometra erinacei plerocercoids fixed directly in glutaraldehyde; the latter have a shrunken and wrinked appearance with a frontal pit at the apical end (Hatsushika \& Okino, 1987). The present study recorded considerably high prevalence of plerocercoid larvae in as many as six anuran species, all of which have use in traditional medicine or local cuisine among the natives of Nagaland. Highly endemic foci of amphibian borne zoonoses, sparganosis in particular, are known to occur among populations in the neighbouring southeastern and eastern countries where similar practices are prevalent (Mastura et al., 1995a,b). Tropical and oriental forms of spargana occur in frogs (Bonne, 1942; Huang \& Kirk, 1962). Dissemination of this zoonotic infection among the native population of Nagaland, therefore, needs to be ascertained.

\section{Acknowledgements}

This study was supported by the Departmental Research Support Program of the University Grants Commission to the Department of Zoology, North Eastern Hill University. Financial support to RI from the State Government of Nagaland is thankfully acknowledged. The SEM facility was kindly made available by the Head, Regional Sophisticated Instrumentation Center at NEHU.

\section{References}

Arora, B.M. (1994). Wildlife Diseases in India (Infectious Diseases of Mammals, Reptiles and Amphibians). New Delhi, 183pp.

Bodri, M.S. (1994). Comparative parasitic diseases of reptiles and amphibians. Proc. Amer. Assos. Vet. Animals Conf. Pittsburgh, U.S.A. $10: 22-27$

Bonne, C. (1942). Researches on Sparganosis in the Netherlands East Indies. Am. J. Trop. Med. 22: 643-645.

Diengdoh, C.A.R. (1989). Helminth parasite spectrum of amphibian hosts in Meghalaya. Ph. D. Thesis, North- Eastern Hill University, Shillong, 129pp.

Dutta, S.K. (1997). Amphibians of India and Sri Lanka (Checklist and Bibliography). Odyssey Publ. House, Bhubaneswar, India, 342pp. Hatsushika, R. and T. Okino (1987). Studies on the head structure of Spirometra erinacei (Cestoda, Pseudophyllidea) Plerocercoid by new streching-fixation method. Kawasaki Med.J. 13: 1-5.

Hoeden, J.V.D. (1964). Zoonosis. Elsevier, New York, 774pp.

Huang, C.T. and R. Kirk (1962). Human sparganosis in Hong Kong. J.Trop. Med. Hyg. 65: 133-138.

Iwata, S. (1972). Experimental and morphological studies of Manson's tapeworm, Diphyllobothrium erinacei (Rudolphi). Special reference with its scientific name and relationship with Sparganum proliferum Ijima. Proc. Med. Parasitol. Japan 4: 536-590.

Kittiponghansa, S., S. Tesana and R. Ritch (1988). Ocular sparganosis; a cause of subconjunctival tumor and deafness. J.Trop. Med. Parasitol. 39: 247-248. 
Table 1. Prevalence and intensity of plerocercoid larvae in anuran hosts in Nagaland

\begin{tabular}{|c|c|c|c|c|c|c|}
\hline Host Species & $\begin{array}{l}\text { No. examined } \\
\text { (infected) }\end{array}$ & $\begin{array}{l}\text { Prevalence } \\
\%(M, F)\end{array}$ & $\begin{array}{l}\text { No. of } \\
\text { parasites } \\
\text { recovered }\end{array}$ & Range & Intensity & $\begin{array}{l}\text { Mean } \\
\text { inten- } \\
\text { sity }\end{array}$ \\
\hline \multicolumn{7}{|l|}{ Dimapur } \\
\hline Rana sp. & $43(7)$ & $16.27(71.4,28.5)$ & 10 & $1-2$ & 1.42 & 023 \\
\hline Hoplobatrachus tigerinus & $23(13)$ & $12.03(58.8,46.1)$ & 20 & $2-6$ & 1.53 & 0.18 \\
\hline Euphlyctis cyanophlyctis & $108(8)$ & $7.40(37.5,62.5)$ & 11 & $1-3$ & 1.25 & 0.1 \\
\hline Polypedatus leucomystax & $25(12)$ & $48(75,25)$ & 19 & $1-7$ & 1.5 & 0.17 \\
\hline \multicolumn{7}{|l|}{ Kohima } \\
\hline Euphlyctis cyanophlyctis & $60(5)$ & $8.3(20,80)$ & 8 & $1-4$ & 1.6 & 0.13 \\
\hline Rhacophorus reinwardtii & $8(1)$ & $12.5(100,0)$ & 1 & - & 1 & 0.12 \\
\hline \multicolumn{7}{|l|}{ Mokokchung } \\
\hline Euphlyctis cyanophlyctis & $50(3)$ & $6(0,100)$ & 7 & $2-3$ & 2.3 & 0.04 \\
\hline Rhacophorus nigropalmatus & $40(3)$ & $7.5(66.6,33.3)$ & 11 & $2-6$ & 3.66 & 0.27 \\
\hline Polypedatus leucomystax & $47(23)$ & $48.93(56.5,43.4)$ & 89 & $2-18$ & 3.88 & 1.89 \\
\hline
\end{tabular}

$\mathrm{M}=$ Male $; \mathrm{F}=$ Female

Intensity = Number of individuals of a parasite species in each infected host in a sample

Mean intensity $=$ Mean number of individuals of a particular parasite species per host examined in a sample.

Kobayashi, E. (1931). Studies on the development of Diphyllobothrium mansoni Cobbold, 1882 (Joyeux, 1927). IV. Hatching of the egg, onchosphere and discarding of the ciliated coat V. The first intermediate host. Taiwan Igakkai Zasshi 15-16: 23-27.

Mastura, A.B., S. Ambu, S. Chandra, B.H. Kiew and R. Rosli (1995a). A preliminry survey of frogs for Spirometra sp. infection- a food borne human parasite. Trop. Biomedicine 12:81-84.

Mastura, A.B., S. Ambu, K.C. Shekhar and O. Hasnah (1995b). Spirometra sp. in Malaysia- $\Lambda$ preliminary study in laboratory animals. Southeast Asian J. Trop. Med. Public Health 26: 450-452.

Miyazaki, 1. (1991). Helminthic Zoonoses. International Medical Foundation. Japan. Tokyo (SEAMIC Publ. No. 62), 494pp.

Mucller, J.F. (1938). The life history of Diphy/lobothrium mansonoides (Mucller. 1935) and some considerations with regard to sparganosis in the United States. Am. J. Trop. Med. 18:41-66.

Roy, B. and V. Tandon (1991). Usefulness of tetramethylsilane in the preparation of helminth parasites for electron microscopy. Rev: Parasitoi 8: 405-413.

Shen, J. (1988). Natural infection of sparganum in frogs and toads in suburbs of Gaungzhau. Chinese J. Parasitol. Parasitic Dis. 6: 120.

Simyth, J.D. and M.M. Smyth (1980). Frogs as Host-parasite Systems 1. In Introduction to Parasitology through the parasites of Rana temporaria, R. esculenta and R. pipiens. Macmillan, London, Basingsioke, $112 \mathrm{pp}$.

Suzuki, N., I. Kumazawa and H. Hosogi (1982). A case of human infection with the adult of Spirometra erinacei (Rudolphi. 1819) Faust, Campbell and Kellog, 1929. Jpn. J. Parasitol. 31:23-26.

Tansurat, P. (1966). Human sparganosis in Thailand. J. Med. Assos Thailand 49: 391-395.

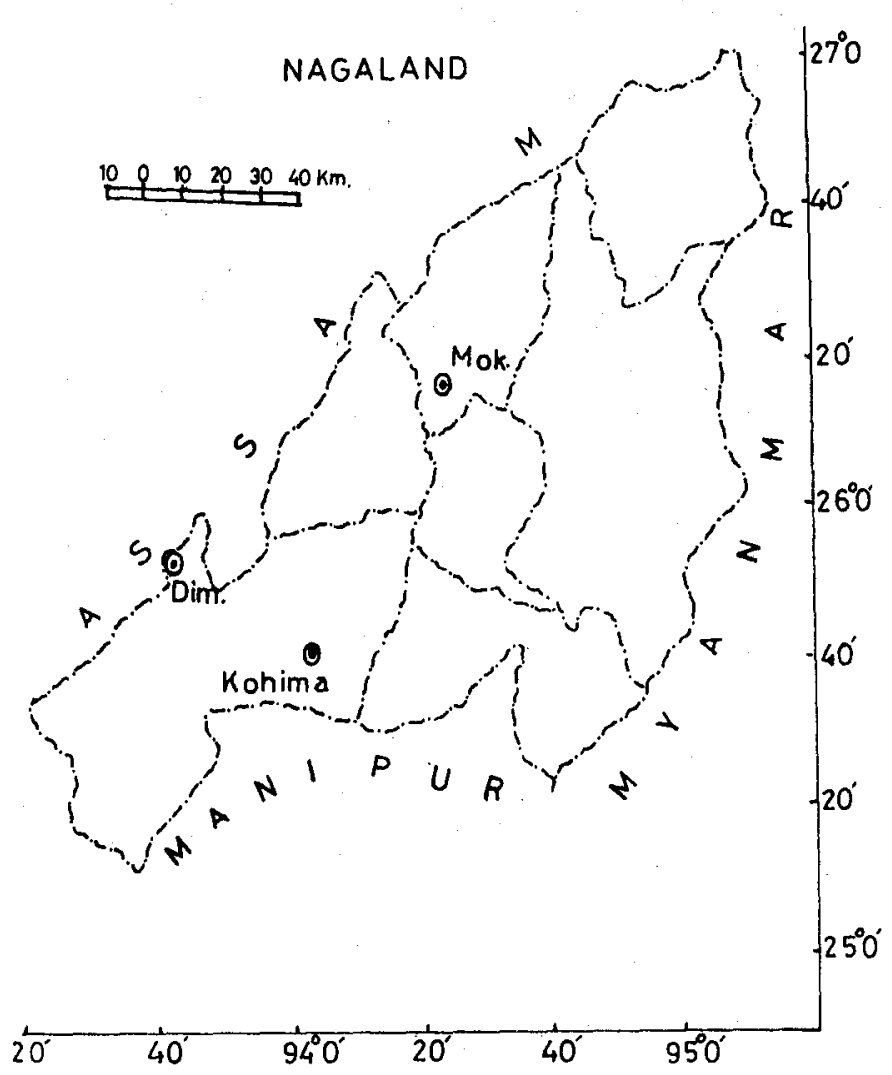

Figure 1. Localities of collection in Nagaland State 

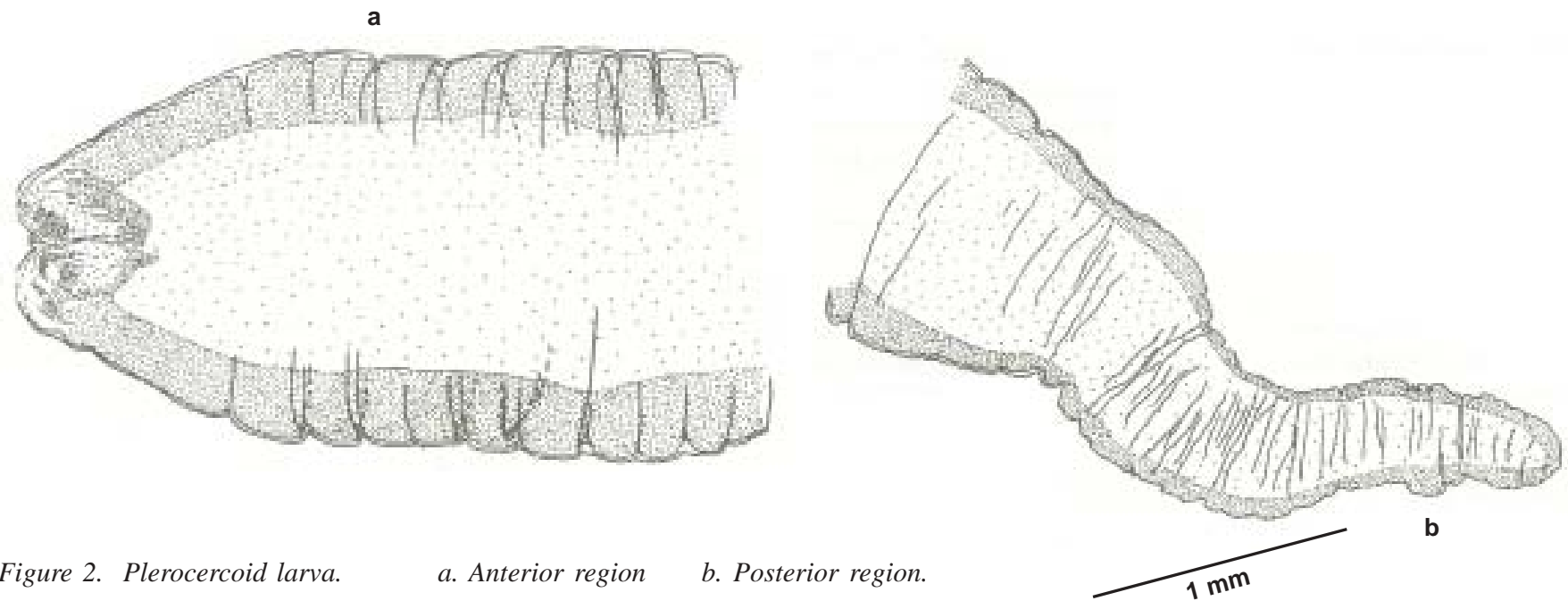

Figure 2. Plerocercoid larva.

a. Anterior region

b. Posterior region.
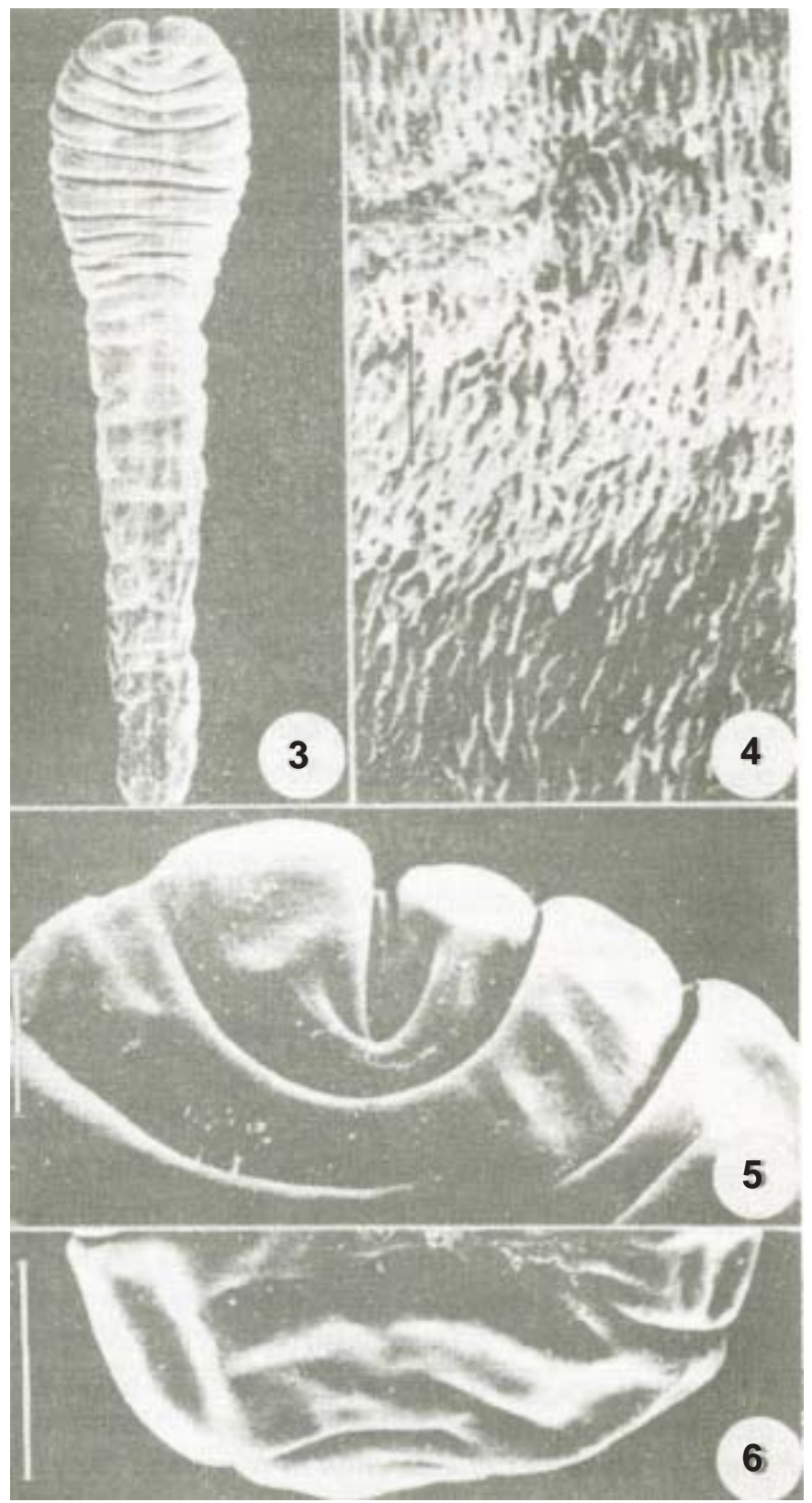

Figure 3-5. Plerocercoid larva-scanning electron micrographs.

3. Full worm (scale bar $=100 \mu \mathrm{m}$ )..

4. Body tegument under higher resolution, showing microtriches (scale bar $=10 \mu \mathrm{m}$ ).

5. Magnified view of the apical end, showing the frontal pit and tegumental foldings (scale bar $=100 \mu \mathrm{m}$ ).

6. The posterior blunt end (scale bar $=100 \mu \mathrm{m}$ ). 